\title{
Desempenho agronômico e econômico do milho em diferentes níveis de manejo e épocas de semeadura
}

\author{
Everton Leonardo Forsthofer ${ }^{(1)}$, Paulo Regis Ferreira da Silva( ${ }^{(2)}$, Mércio Luiz Strieder ${ }^{(2)}$, Tarcísio Minetto ${ }^{(3)}$, \\ Lisandro Rambo(2) $^{(2)}$ Gilber Argenta(1) $^{(1)}$ Luis Sangoi( ${ }^{(4)}$, Elias Suhre ${ }^{(2)}$ e Adriano Alves da Silva(2)
}

\begin{abstract}
(1)Syngenta Seeds Ltda., Rua Maria Silva, Quadra 30, Lote 03, Setor Morada do Sol, CEP 75908-660 Rio Verde, GO. E-mail: everton.forsthofer@syngenta.com (2)Universidade Federal do Rio Grande do Sul, Fac. de Agronomia, Dep. de Plantas de Lavoura, Caixa Postal 15.100, CEP 90970-100 Porto Alegre, RS. E-mail: paulo.silva@ufrgs.br (3)Federação das Cooperativas Agropecuárias do Rio Grande do Sul Ltda., Rua dos Andradas, no 1.137, Conjunto 902, CEP 90027-900 Porto Alegre, RS. E-mail: fecoagro@redeagro.com.br (4)Universidade do Estado de Santa Catarina, Centro de Ciências Agroveterinárias, Caixa Postal 281, CEP 88520-000 Lages, SC. E-mail: a2ls@cav.udesc.br
\end{abstract}

Resumo - O objetivo deste trabalho foi avaliar o desempenho agronômico e econômico do milho em cinco níveis de manejo e três épocas de semeadura. O experimento foi conduzido nos anos agrícolas 2001/2002 e 2002/2003, em Eldorado do Sul, RS, Brasil. Os tratamentos constaram de três épocas de semeadura (agosto, outubro e dezembro) e cinco níveis de manejo (baixo, médio, alto, potenciais I e II), diferenciados quanto à espécie de cobertura do solo no inverno, à cultivar, ao arranjo de plantas, ao nível de adubação química, ao regime hídrico e ao controle de plantas daninhas, pragas e doenças. O delineamento experimental utilizado foi o de blocos ao acaso, dispostos em parcelas subdivididas, com quatro repetições. O fator época de semeadura foi locado na parcela principal e os níveis de manejo, na subparcela. Com a melhoria das práticas de manejo e adoção de cultivares com maior potencial produtivo, houve maior rendimento de grãos nas semeaduras de agosto e de outubro, o que propiciou maior retorno econômico, principalmente na semeadura de outubro. Em dezembro, não ocorreu retorno econômico ao maior investimento realizado em manejo. Em agosto e outubro, foi possível associar as máximas eficiências técnica e econômica, por meio do aumento do nível de manejo e da escolha de cultivar com maior potencial de rendimento.

Termos para indexação: Zea mays, eficiência técnica e econômica, cultivares, regime hídrico, rendimento de grãos, margem bruta.

\section{Agronomic yield and economic performance of maize in different management levels and sowing times}

\begin{abstract}
The objective of this work was to evaluate agronomic and economic performance of maize in five management levels and three sowing times. The experiment was conducted in 2001/2002 and 2002/2003, in Eldorado do Sul, RS, Brazil. Treatments consisted of three sowing times (August, October and December) and five management levels (low, average, high, potential I and II) which varied in relation to the soil winter cover, cultivar, plant arrangement and the level of chemical fertilizer, water supply and weed, insect and disease control. A randomized block design was used with split-plots and four replications. Sowing times were located in the main plots and the management level in the split-plots. The increments in maize yield in response to investments in management and cultivar were higher in August and October, and resulted in higher economic return, mainly in October. In December sowing, there was no economic return for the highest investment in management level. In August and October, it was possible to associate maximal economic and technical efficiencies through the management level increase and the choice of the greater potential yield cultivar.
\end{abstract}

Index terms: Zea mays, agronomic and economic efficiency, cultivars, water regime, grain yield, gross margin.

\section{Introdução}

A manifestação do potencial de rendimento de grãos das culturas depende de fatores genéticos e de condições favoráveis de ambiente e de manejo (Bugbee \& Salisbury, 1988; Evans \& Fischer, 1999). Em regiões de clima subtropical, como no Rio Grande do Sul, além da posição geográfica, os fatores ambientais exercem influência na época de semeadura. As variações da temperatura do ar, das disponibilidades de radiação e hídrica influenciam a fenologia, o crescimento e o desenvolvimento da planta (Lozada \& Angelocci, 1999; Stone et al., 1999). 
O potencial de rendimento de grãos, definido pela interação genótipo-ambiente (Loomis \& Amthor, 1999; Tollenaar \& Lee, 2002), pode ser maximizado por meio da escolha adequada da época de semeadura, sem sobrecarregar, significativamente, o custo de produção.

Além dos fatores intrínsecos à planta e das condições climáticas da região de cultivo, o manejo dado à cultura interfere na produção de fitomassa, na interceptação da radiação solar e na acumulação de fotoassimilados e, portanto, no rendimento de grãos (Argenta et al., 2001). O potencial de rendimento de grãos, a ser obtido em cada época de semeadura, dependerá principalmente da quantidade de radiação solar incidente, da eficiência de interceptação e de conversão da radiação interceptada em fitomassa, e da eficiência de partição de assimilados à estrutura de interesse econômico (Andrade, 1995). A quantidade de radiação incidente disponível varia com a posição geográfica de cada região produtora de grãos, ou seja, com sua latitude e altitude (Gardner et al., 1985; Stone et al., 1999), e de acordo com a época de semeadura da cultura. A eficiência de interceptação da radiação e de sua conversão e partição em produtos orgânicos depende de fatores climáticos, com destaque para temperatura do ar e disponibilidade hídrica; fatores edáficos, com ênfase na fertilidade natural, estrutura e textura do solo; e do manejo, destacando-se práticas culturais que interfiram sobre o arranjo de plantas (Argenta et al., 2001; Sangoi, 2001).

Nas últimas três safras agrícolas (2001/2002 a 2003/ 2004), os rendimentos médios de grãos de milho obtidos pelos produtores brasileiros situaram-se em torno de 3,3 t ha-1 (Conab, 2004). Sangoi et al. (2003), ao avaliar o retorno técnico e econômico da cultura do milho, em cinco níveis de manejo, em Eldorado do Sul, RS (Depressão Central), e em Lages, SC (Planalto Serrano), obtiveram rendimentos bem superiores a essa média. Nos dois locais, o rendimento de grãos e a margem bruta obtida por hectare aumentaram com a elevação do nível de manejo utilizado, tendo variado de 3 a 15 t ha $^{-1}$ e R $\$ 105,00$ a R \$ 725,00, em Eldorado do Sul, RS, e de 3,2 a 15,9 $\mathrm{t} \mathrm{ha}^{-1}$ e R\$ 131,00 a R \$ 1.093,00, em Lages, SC. Nesse estudo, foi determinada a resposta do milho à melhoria do nível de manejo em apenas uma época de semeadura - a de outubro. Isso pode ser atribuído ao uso de variedades com baixo potencial produtivo, à época de semeadura inadequada, à densidade de plantas, ao estresse hídrico e nutricional, e às deficiências no controle de pragas, doenças e plantas daninhas durante estádios críticos de desenvolvimento da planta, podendo ocorrer efeito isolado ou interação entre estes.

O estudo do potencial de rendimento de grãos de milho, em diferentes níveis de manejo e épocas de semeadura, possibilita a identificação dos fatores ambientais que limitam seu cultivo, em cada época de semeadura. Com base no conhecimento e na mensuração dos fatores que interferem no rendimento de grãos, nos diferentes níveis e sistemas produtivos, poderão ser traçadas estratégias de manejo e adotadas indicações viáveis, para minimizar ou superar as deficiências verificadas em cada nível de manejo utilizado. Com isso, a identificação de sistemas de manejo adequados para cada época de semeadura permitirá ao produtor rural otimizar os recursos existentes na propriedade e maximizar a renda bruta, preservando os recursos do ambiente.

O objetivo deste trabalho foi avaliar, durante duas estações de crescimento, o desempenho agronômico e econômico do milho, em cinco níveis de manejo e em três épocas de semeadura.

\section{Material e Métodos}

O experimento foi conduzido em duas estações de crescimento (2001/2002 e 2002/2003), na Estação Experimental Agronômica da Universidade Federal do Rio Grande do Sul (EEA/UFRGS), localizada em Eldorado

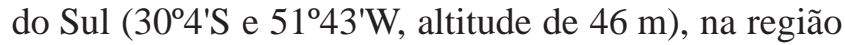
ecoclimática da Depressão Central do Estado do Rio Grande do Sul (Bergamaschi et al., 2003). O clima da região, segundo classificação de Köppen, é subtropical úmido de verão quente, do tipo fundamental $\mathrm{Cfa}$, predominante no Sul do Brasil. A precipitação média anual é de $1.440 \mathrm{~mm}$, dos quais $425 \mathrm{~mm}$ são concentrados nos meses de novembro a fevereiro, período que abrange os estádios de enchimento de grãos, nas três épocas de semeadura adotadas nos dois experimentos.

No cálculo dos balanços hídricos relativos às duas estações de condução dos experimentos, foram utilizados os dados meteorológicos referentes à precipitação, às temperaturas máxima e mínima do ar, à evapotranspiração e à radiação solar global. Esses dados foram coletados na unidade meteorológica da EEAUFRGS, e as estimativas foram realizadas segundo o método de Thorntwaite \& Mather (1955) citados por Bergamaschi et al. (2003).

O solo da área experimental pertence à unidade de mapeamento São Jerônimo e é classificado como Argissolo Vermelho distrófico típico. Os atributos físicos 
e químicos do solo da área experimental, no primeiro e no segundo ano, foram, respectivamente: argila, 29 e 34\%; pH (água), 4,8 e 5,6; índice SMP, 5,8 e 6,2; P, 18 e $7,1 \mathrm{mg} \mathrm{L}^{-1} ; \mathrm{K}, 145$ e $122 \mathrm{mg} \mathrm{L}^{-1}$; MO, 20 e $27 \mathrm{~g} \mathrm{~kg}^{-1}$; e CTC, 17,6 e $7,6 \mathrm{cmol}_{\mathrm{C}} \mathrm{L}^{-1}$.

Nos dois anos agrícolas, os tratamentos constaram de cinco níveis de manejo e três épocas de semeadura de milho. O delineamento experimental utilizado foi o de blocos ao acaso, dispostos em parcelas subdivididas, com quatro repetições. O fator época de semeadura foi locado na parcela principal e os níveis de manejo, na subparcela. Os níveis de manejo variaram quanto ao tipo de cobertura de solo no inverno, à cultivar, aos níveis de adubação (base e de cobertura), ao arranjo de plantas, ao regime hídrico e ao nível de controle de plantas daninhas e de pragas (Tabela 1).
As semeaduras ocorreram em agosto (precoce), outubro (intermediária) e dezembro (tardia), conforme indicações técnicas vigentes para a cultura do milho no Rio Grande do Sul. Os níveis de manejo baixo, médio e alto também foram feitos conforme indicações técnicas, exceto quanto à adubação nitrogenada, que seguiu a indicação de Amado et al. (2002). Os níveis de manejo potenciais I e II foram propostos para potencializar o rendimento de grãos, fundamentados em resultados de pesquisas locais obtidos por Argenta et al. (2001).

As cultivares de milho adotadas (Tabela 1) foram implantadas com semeadora manual, em sistema de semeadura direta, em sucessão ao nabo forrageiro (Raphanus sativus) na semeadura de agosto, à ervilhaca comum (Vicia sativa), na de outubro, e à aveiapreta (Avena strigosa), na de dezembro. Essas cobertu-

Tabela 1. Caracterização dos níveis de manejo, aplicados nos dois anos de condução do experimento (2001/2002 e 2002/2003) na cultura do milho, em três épocas de semeadura, em Eldorado do Sul, RS.

\begin{tabular}{|c|c|c|c|c|c|c|c|c|c|c|c|}
\hline \multirow{3}{*}{$\begin{array}{l}\text { Época de } \\
\text { semeadura }\end{array}$} & \multirow{3}{*}{$\begin{array}{l}\text { Cultura no } \\
\text { inverno }\end{array}$} & \multirow{3}{*}{$\begin{array}{l}\text { Nível de } \\
\text { manejo }\end{array}$} & \multirow{3}{*}{ Cultivar $^{(1)}$} & \multicolumn{5}{|c|}{ Adubação $\left(\mathrm{kg} \mathrm{ha}^{-1}\right)$} & \multirow{3}{*}{$\begin{array}{l}\text { Irrigação } \\
\text { suplementar }\end{array}$} & \multirow{3}{*}{$\begin{array}{l}\text { Densidade }^{(5)} \\
\quad\left(\mathrm{pl} \mathrm{m}^{-2}\right)\end{array}$} & \multirow{3}{*}{$\begin{array}{c}\text { Espaçamento } \\
\text { entre linhas }{ }^{(6)} \\
(\mathrm{cm})\end{array}$} \\
\hline & & & & \multirow{2}{*}{$\begin{array}{l}\text { Base } \\
\mathrm{N}^{(2)} \\
\end{array}$} & \multirow{2}{*}{$\begin{array}{c}\text { Cobertura } \\
\mathrm{N}^{(2)}\end{array}$} & \multicolumn{2}{|c|}{ Semeadura } & \multirow{2}{*}{$\begin{array}{c}\text { Micro- } \\
\text { nutrientes }\end{array}$} & & & \\
\hline & & & & & & $\mathrm{P}_{2} \mathrm{O}_{5}^{(3)}$ & $\mathrm{K}_{2} \mathrm{O}^{(3)}$ & & & & \\
\hline \multirow{5}{*}{$\begin{array}{l}\text { Agosto } \\
\text { (Precoce) } \\
(28 / 8 / 2001) \\
(26 / 8 / 2002)\end{array}$} & \multirow{5}{*}{$\begin{array}{l}\text { Nabo } \\
\text { forrageiro }\end{array}$} & Baixo & F 35 & 0 & 16 & 20 & 24 & Sem & Sem & 4,5 & 80 \\
\hline & & Médio & DKB 701 & 15 & 17 & 32 & 48 & Sem & Sem & 5,5 & 80 \\
\hline & & Alto & P 32R21 & 15 & 65 & 56 & 80 & Sem & Com & 7,5 & 80 \\
\hline & & Potencial I & P 32R21 & 15 & 145 & 84 & 120 & Com & Com & 8,5 & 40 \\
\hline & & Potencial II & I P 32R21 & 15 & 161 & 93 & 132 & Com & Com & 11,0 & 40 \\
\hline \multirow{5}{*}{$\begin{array}{l}\text { Outubro } \\
\text { (Intermediária) } \\
(16 / 10 / 2001) \\
(17 / 10 / 2002)\end{array}$} & \multirow{5}{*}{$\begin{array}{l}\text { Ervilhaca } \\
\text { comum }\end{array}$} & Baixo & F 35 & 0 & 20 & 25 & 30 & Sem & Sem & 4,0 & 80 \\
\hline & & Médio & DKB 701 & 0 & 40 & 40 & 60 & Sem & Sem & 5,0 & 80 \\
\hline & & Alto & P 32R21 & 0 & 100 & 70 & 100 & Sem & Com & 7,0 & 80 \\
\hline & & Potencial I & P 32R21 & 0 & 200 & 105 & 150 & Com & Com & 8,0 & 40 \\
\hline & & Potencial II & I P 32R21 & 0 & 220 & 116 & 165 & Com & Com & 10,0 & 40 \\
\hline \multirow{5}{*}{$\begin{array}{l}\text { Dezembro } \\
\text { (Tardia) } \\
(17 / 12 / 2001) \\
(16 / 12 / 2002)\end{array}$} & \multirow{5}{*}{$\begin{array}{l}\text { Aveia- } \\
\text { preta }\end{array}$} & Baixo & F 35 & 20 & 20 & 18 & 21 & Sem & Sem & 4,0 & 80 \\
\hline & & Médio & DKB 701 & 30 & 30 & 28 & 42 & Sem & Sem & 5,0 & 80 \\
\hline & & Alto & P 30F33 & 30 & 70 & 49 & 70 & Sem & Com & 7,0 & 80 \\
\hline & & Potencial I & P 30F33 & 30 & 150 & 74 & 105 & Com & Com & 8,0 & 40 \\
\hline & & Potencial II & I P 30F33 & 30 & 168 & 82 & 116 & Com & Com & 10,0 & 40 \\
\hline
\end{tabular}

(1)Caracterização das cultivares: Fundacep F 35 - ciclo normal, variedade de polinização aberta; Monsanto DKB 701 - ciclo precoce e híbrido duplo; Pioneer P 32R21 - ciclo superprecoce e híbrido simples. ${ }^{(2)}$ A adubação nitrogenada na forma de uréia (45\% N), utilizada nos níveis baixo, médio e alto, foi baseada em Amado et al. (2002); consideraram-se as expectativas de rendimento de 3-6, 6-9 e >9 t ha ${ }^{-1}$, respectivamente, para os níveis baixo, médio e alto; nos níveis potenciais I e II a proposta visou a potencializar o rendimento de grãos. (3)As adubações fosfatada e potássica, respectivamente, na forma de superfosfato triplo $\left(42 \% \mathrm{P}_{2} \mathrm{O}_{5}\right)$ e cloreto de potássio $\left(60 \% \mathrm{~K}_{2} \mathrm{O}\right)$, utilizadas nos níveis baixo, médio e alto foram de acordo com indicações técnicas vigentes para a cultura do milho no RS; as doses de P e K basearam-se no valor de reposição dentro da expectativa de rendimento; nos níveis potenciais I e II, a adubação proposta visou a potencializar o rendimento de grãos. (4)Nos níveis potenciais I e II, foram aplicados os micronutrientes óxido de zinco, molibdênio e boro, nas doses de 125, 5 e 1 g por 100 kg de sementes e também via foliar, quando as plantas de milho apresentavam 7-8 folhas completamente expandidas. ${ }^{(5)}$ A densidade de plantas, utilizada nos níveis baixo, médio e alto, baseou-se no nível de manejo, na expectativa de rendimento de grãos e no desenvolvimento vegetativo das plantas; nos demais níveis, baseou-se em resultados de experimentos locais (Argenta et al., 2001); na semeadura, em agosto, foram adotadas maiores densidades de plantas, para compensar o menor desenvolvimento dessas, em razão das temperaturas mais baixas de solo e do ar, o que resultou em menores estatura de planta, expansão de folhas e índice de área foliar. ${ }^{(6)} \mathrm{O}$ espaçamento entre linhas utilizado nos níveis baixo, médio e alto baseou-se nas indicações técnicas vigentes para a cultura do milho no Rio Grande do Sul, e nos demais níveis de manejo, em resultados de experimentos locais (Argenta et al., 2001). 
ras foram implantadas com densidades de 12 , 80 e $100 \mathrm{~kg} \mathrm{ha}^{-1}$ de sementes, respectivamente, sem adubação de base. Em ambos os anos de condução do estudo, 20 dias depois da emergência, foram aplicados $30 \mathrm{~kg} \mathrm{ha}^{-1}$ de N nas culturas de nabo forrageiro e de aveia-preta.

Na semeadura de agosto, o nabo forrageiro foi manejado com rolo-faca no dia da semeadura do milho, enquanto na época de outubro não se realizou nenhuma prática de manejo sobre a ervilhaca comum. Na semeadura de dezembro, a aveia-preta foi dessecada com glifosato (540 $\mathrm{g} \mathrm{ha}^{-1}$ do i.a.), quando $50 \%$ das plantas estavam em pleno florescimento. A adubação do milho foi realizada na linha, por ocasião da semeadura, conforme quantidades propostas em cada nível de manejo (Tabela 1). Nos níveis de manejo baixo, médio e alto, o fósforo e o potássio foram aplicados no momento da semeadura. Nos níveis potenciais I e II, metade da dose de potássio foi aplicada na semeadura e o restante no estádio de seis folhas expandidas.

A adubação nitrogenada no milho variou de acordo com a espécie de cobertura do solo no inverno e com o nível de manejo. Na época precoce, $15 \mathrm{~kg} \mathrm{ha}^{-1} \mathrm{de} \mathrm{N}$ foram aplicados na semeadura e o restante em cobertura, em todos os níveis de manejo, exceto no manejo baixo, em que não se aplicou $\mathrm{N}$ na semeadura. Na época intermediária, foi realizada aplicação de $\mathrm{N}$ apenas em cobertura, já que a ervilhaca comum pode liberar até $60 \%$ do $\mathrm{N}$ de seus resíduos durante os primeiros 30 dias depois do seu manejo (Aita \& Giacomini, 2003). Na época tardia (dezembro), foram aplicados $30 \mathrm{~kg} \mathrm{ha}^{-1}$ de $\mathrm{N}$ na semeadura e o restante em cobertura, exceto no nível de manejo baixo, em que foram aplicados $20 \mathrm{~kg} \mathrm{ha}^{-1}$ de $\mathrm{N}$ na semeadura.

Nos níveis de manejo baixo e médio, o $\mathrm{N}$ em cobertura foi aplicado no estádio de seis folhas expandidas. No nível de manejo alto, metade do $\mathrm{N}$ em cobertura foi aplicado no estádio de três folhas, e o restante no de seis folhas expandidas. Nos níveis potenciais, a quantidade de $\mathrm{N}$ em cobertura foi dividida em quatro doses iguais, aplicadas nos estádios de três, seis e dez folhas expandidas e no espigamento. Nesses dois níveis de manejo, foram aplicados micronutrientes por ocasião do tratamento de sementes com inseticida e, por via foliar, no estádio de oito folhas expandidas (Tabela 1).

Quando as plantas de milho estavam com três folhas expandidas, foi realizado desbaste, e o número de plantas foi ajustado às densidades estabelecidas em cada nível de manejo (Tabela 1). Nos níveis de manejo alto e potenciais I e II, realizou-se o controle adequado de pragas, assim como suplementação hídrica por sistema de aspersão, quando o potencial de água no solo era inferior a $-0,04 \mathrm{MPa}$. O manejo de invasoras foi realizado com atrazine + simazine $\left(1.500+1.500 \mathrm{~g} \mathrm{ha}^{-1}\right.$ do i.a. $)$, em pós-emergência precoce, em todos os níveis de manejo, tendo sido realizada uma aplicação nos níveis baixo e médio e duas nos níveis de manejo alto e potenciais I e II.

As determinações realizadas nos dois anos foram: rendimento de grãos, número de espigas por $\mathrm{m}^{2}$, número de grãos por $\mathrm{m}^{2}$, peso do grão e desempenho econômico. A análise econômica foi baseada no método descrito em Minetto (2001), usando o termo margem bruta para quantificar a diferença entre receita bruta obtida e dispêndio efetuado em cada nível de manejo, pois no total do dispêndio não foram consideradas remunerações à terra, às instalações e às construções, nem juros sobre o desembolso. Por meio do SAS, os dados de rendimento de grãos e seus componentes foram analisados de forma conjunta, mediante análise de variância pelo teste $\mathrm{F}$ a $5 \%$ de probabilidade, considerando-se a época de semeadura como fator aleatório. As médias foram comparadas pelo teste de Duncan a 5\% de probabilidade

\section{Resultados e Discussão}

No ano agrícola 2001/2002, observou-se deficit hídrico de pequena intensidade, inferior a $10 \mathrm{~mm}$ por decêndio, nos meses de dezembro de 2001 e janeiro de 2002 (Figura 1). O deficit de maior intensidade desse ano agrícola foi observado no segundo decêndio de fevereiro. No segundo ano de condução da pesquisa, o período mais intenso de deficiência hídrica ocorreu entre o segundo decêndio de janeiro e o primeiro decêndio de fevereiro de 2003. Nos dois anos de condução do experimento, constatou-se que o período de deficiência hídrica iniciou-se tardiamente e foi de menor intensidade, quando comparado com a média do período entre 1969 e 1999 (Figura 1). Segundo Andrade et al. (1999), embora de pequena magnitude, a menor disponibilidade hídrica e de nutrientes pode resultar em menor desenvolvimento da planta, menor acúmulo de fotoassimilados e menor produção de grãos.

Quanto às variações na disponibilidade de radiação solar global e da temperatura do ar, observaram-se pequenas diferenças entre os valores verificados nos dois anos de condução do experimento e a média do período entre 1969 e 1999 (Figura 1). A radiação solar diária oscilou entre 160 e $560 \mathrm{cal} \mathrm{cm}^{-2}$ por dia, e a temperatura média do ar variou entre 13 e $26^{\circ} \mathrm{C}$, durante a estação de crescimento da cultura. Essas características são 
relevantes, pois a duração do subperíodo semeaduraespigamento possui relação linear com a temperatura do solo e do ar (Stone et al., 1999), enquanto a duração
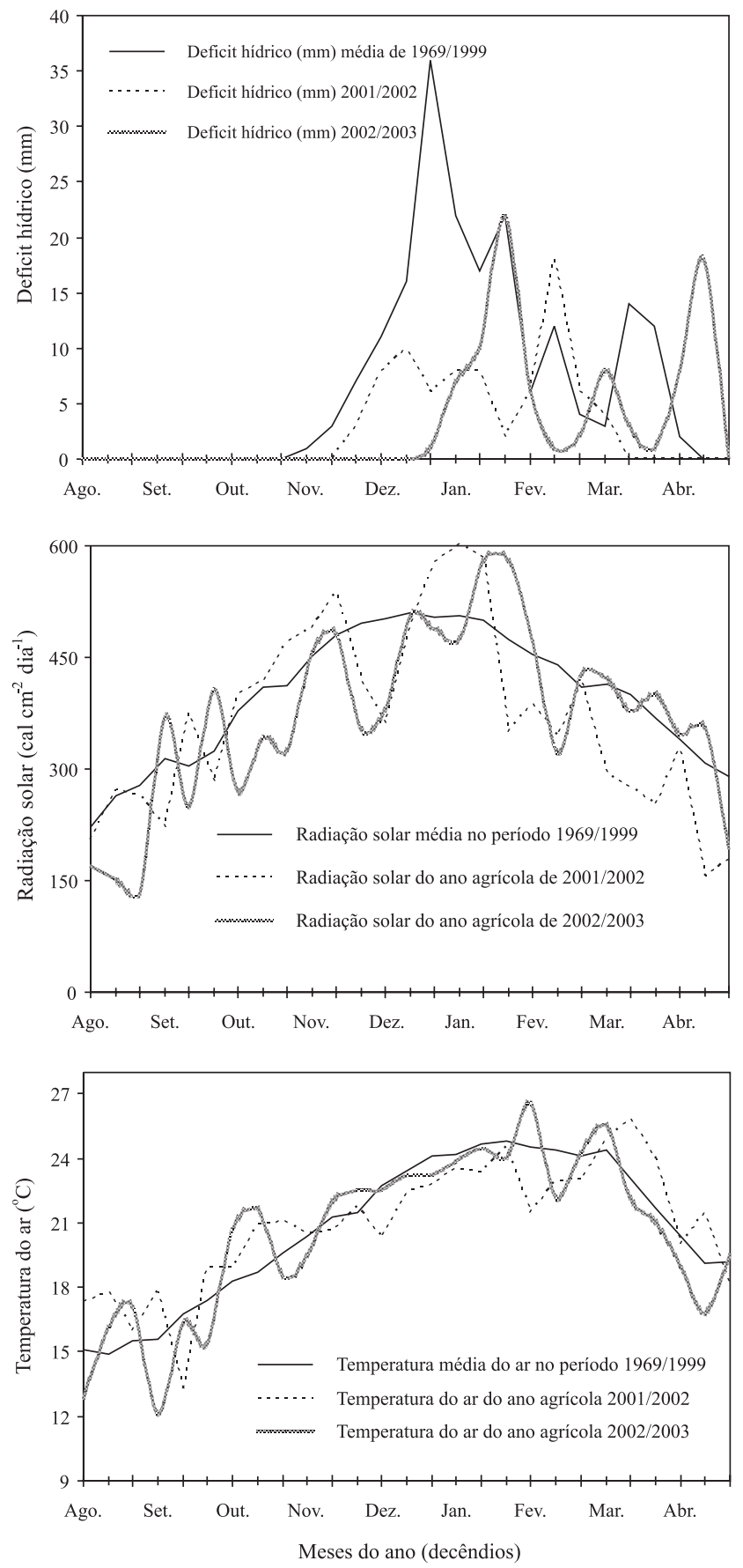

Figura 1. Deficit hídrico, radiação solar global e temperatura média do ar por decêndio, relativo aos anos agrícolas 2001/ 2002 e 2002/2003 e à média do período entre 1969 e 1999, em Eldorado do Sul, RS. Dados do Setor de Agrometeorologia da UFRGS. do subperíodo espigamento-maturação fisiológica apresenta baixa correlação com temperatura do ar (Lozada \& Angelocci, 1999), o que pode ter afetado o ciclo da cultura nos diferentes níveis de manejo.

O primeiro componente do rendimento de grãos a ser definido é o número de espigas por $\mathrm{m}^{2}$, que está diretamente associado à densidade de plantas. Na análise conjunta dos resultados, nas três épocas de semeadura, o número de espigas por $\mathrm{m}^{2}$ aumentou à medida que se elevou o nível de manejo de baixo para o potencial II, em razão dos incrementos na densidade de plantas, na disponibilidade hídrica e nutricional e pelo uso de cultivares mais responsivas (Tabela 2).

Tabela 2. Componentes do rendimento e rendimento de grãos de milho em cinco níveis de manejo, em três épocas de semeadura, na média de dois anos agrícolas (2001/2002 e 2002/ 2003), em Eldorado do Sul, RS ${ }^{(1)}$.

\begin{tabular}{|c|c|c|c|}
\hline \multirow{2}{*}{$\begin{array}{l}\text { Nível de } \\
\text { manejo }\end{array}$} & \multicolumn{3}{|c|}{ Época de semeadura } \\
\hline & Agosto & Outubro & Dezembro \\
\hline & \multicolumn{3}{|c|}{ Número de espigas por $\mathrm{m}^{2}$} \\
\hline Baixo & $4,1 \mathrm{Ad}$ & 3,7Ad & 3,9Ae \\
\hline Médio & $4,8 \mathrm{ABd}$ & $4,5 \mathrm{Bd}$ & $5,1 \mathrm{Ad}$ \\
\hline Alto & $7,1 \mathrm{Ac}$ & $6,8 \mathrm{Ac}$ & $7,1 \mathrm{Ac}$ \\
\hline Potencial I & $8,2 \mathrm{Ab}$ & $7,9 \mathrm{Ab}$ & $8,1 \mathrm{Ab}$ \\
\hline \multirow[t]{2}{*}{ Potencial II } & $10,8 \mathrm{Aa}$ & $9,8 \mathrm{Ba}$ & $10,0 \mathrm{Aa}$ \\
\hline & \multicolumn{3}{|c|}{ Número de grãos por $\mathrm{m}^{2}$} \\
\hline Baixo & $1.765 \mathrm{Ac}$ & $1.491 \mathrm{Ac}$ & $1.505 \mathrm{Ad}$ \\
\hline Médio & $2.167 \mathrm{Ac}$ & $1.751 \mathrm{Bc}$ & $2.369 \mathrm{Ac}$ \\
\hline Alto & $2.840 \mathrm{Bb}$ & $4.233 \mathrm{Ab}$ & $3.157 \mathrm{Bb}$ \\
\hline Potencial I & $3.152 \mathrm{Bb}$ & $4.274 \mathrm{Ab}$ & $3.501 \mathrm{Bb}$ \\
\hline \multirow[t]{2}{*}{ Potencial II } & $4.121 \mathrm{Ba}$ & 4.908Aa & $4.332 \mathrm{Ba}$ \\
\hline & \multicolumn{3}{|c|}{ Peso do grão $(\mathrm{mg})^{(3)}$} \\
\hline Baixo & $281 \mathrm{Bb}$ & 348Aa & $287 \mathrm{Ba}$ \\
\hline Médio & $284 \mathrm{Bb}$ & $323 \mathrm{Aa}$ & $270 \mathrm{Ba}$ \\
\hline Alto & 308Aa & $270 \mathrm{Bb}$ & $248 \mathrm{Cb}$ \\
\hline Potencial I & $327 \mathrm{Aa}$ & $312 \mathrm{Aab}$ & $262 \mathrm{Ba}$ \\
\hline \multirow[t]{2}{*}{ Potencial II } & $322 \mathrm{Aa}$ & $322 \mathrm{Aa}$ & $241 \mathrm{Bb}$ \\
\hline & \multicolumn{3}{|c|}{ Rendimento de grãos $\left(\mathrm{t} \mathrm{ha}^{-1}\right)$} \\
\hline Baixo & $4,84 \mathrm{Ac}$ & $4,38 \mathrm{Bc}$ & $4,33 \mathrm{Ad}$ \\
\hline Médio & $5,62 \mathrm{ABbc}$ & $4,57 \mathrm{Bc}$ & $6,07 \mathrm{Ac}$ \\
\hline Alto & $6,95 \mathrm{Bb}$ & $10,02 \mathrm{Ab}$ & $7,66 \mathrm{Bbc}$ \\
\hline Potencial I & $9,79 \mathrm{Ba}$ & $13,45 \mathrm{Aa}$ & $8,77 \mathrm{Bab}$ \\
\hline Potencial II & $10,24 \mathrm{Ba}$ & $13,77 \mathrm{Aa}$ & $9,57 \mathrm{Ba}$ \\
\hline
\end{tabular}

${ }^{(1)}$ Médias seguidas da mesma letra, maiúscula na linha (comparação entre épocas) e minúscula na coluna (comparação entre níveis), não diferem entre si pelo teste de Duncan a 5\% de probabilidade. (2)Os níveis de manejo variaram quanto a: tipo de cobertura de solo no inverno, cultivar, níveis de adubação (base e cobertura), arranjo de plantas e regime hídrico. ${ }^{(3)}$ Estimado por meio da contagem manual de 200 grãos, pesagem e correção da umidade a $13 \%$, e pela divisão do valor obtido por 200 . 
O segundo componente a ser definido é o número de grãos por $\mathrm{m}^{2}$, associado à taxa de crescimento da planta entre o pré e o pós-pendoamento (Andrade et al., 1999) e à definição do número de drenos reprodutivos (Didonet et al., 2002), que dependem das condições climáticas vigentes. Neste estudo, o número de grãos por $\mathrm{m}^{2}$ variou de acordo com a interação entre época de semeadura e níveis de manejo da cultura do milho. Assim, nos níveis de manejo baixo e médio, sem suplementação hídrica nas três épocas de semeadura, o número de grãos por $\mathrm{m}^{2}$ foi similar nas semeaduras de agosto, outubro e dezembro (Tabela 2). No nível de manejo médio, tal componente foi menor na semeadura de outubro, em relação às de agosto e dezembro. No entanto, na comparação entre épocas de semeadura dentro do mesmo nível de manejo, naqueles com maior investimento (alto e potenciais I e II), o número de grãos por $\mathrm{m}^{2}$, em outubro, foi superior ao obtido em agosto e dezembro. O melhor arranjo de plantas, a suplementação hídrica e o maior aporte de nutrientes, nestes três níveis de manejo, dentro da mesma época de semeadura, associado às maiores disponibilidades de radiação solar e temperatura do ar na época intermediária, foram condições que permitiram que o rendimento de grãos fosse maximizado quando a semeadura ocorreu no início da primavera. Isto porque o padrão de desenvolvimento da planta e o acúmulo de fotoassimilados são alterados entre as épocas de semeadura e níveis de manejo (Andrade et al., 1999). Tais dados confirmam que as semeaduras efetuadas no início da primavera potencializam o rendimento de grãos de milho no Sul do Brasil, desde que não ocorra deficiência hídrica e haja densidade de plantas, nível nutricional, controle de pragas e invasoras e genética adequada (Silva \& Argenta, 2000).

O rendimento de grãos do milho é linearmente dependente do volume de água disponível, e a distribuição da precipitação é mais importante que a quantidade; a ocorrência de deficits hídricos é comum à cultura no Estado do Rio Grande do Sul (Matzenauer \& Machado, 2002). Nas três épocas de semeadura, o número de grãos por $\mathrm{m}^{2}$ aumentou com a melhoria do nível de manejo e, geralmente, foi maior na semeadura de outubro, corroborando resultados de Sangoi (1993), que trabalhou com quatro épocas de semeadura no Planalto Serrano Catarinense. Os resultados também são explicados pela interação existente entre as variáveis que compõem os tratamentos nos cinco níveis de manejo e pelo fato de a semeadura de outubro permitir coincidir a máxima incidência de radiação solar com o índice de área foliar máximo. Essas variáveis, consideradas na definição dos tratamentos, alteram o padrão de desenvolvimento da planta e, assim, seu rendimento final, pois segundo Andrade et al. (1999), existe relação quadrática entre número de grãos por $\mathrm{m}^{2}$ e a taxa de desenvolvimento da planta, que varia com o arranjo de plantas, radiação solar incidente, temperatura noturna e entre anos.

O último componente do rendimento a ser definido é o peso do grão. Esse componente é determinado pela taxa e pela duração do período de enchimento de grãos (Wang et al., 1999; Didonet et al., 2002). Nos níveis de manejo com menor investimento (baixo e médio), o maior peso do grão foi obtido na época de semeadura de outubro em relação às de agosto e dezembro (Tabela 2). No nível de manejo alto, o maior peso do grão ocorreu na semeadura de agosto e o menor na de dezembro, sendo intermediário o valor obtido na de outubro. Nos níveis de manejo potenciais I e II, o peso do grão foi similar nas semeaduras realizadas em agosto e outubro e superior ao peso obtido na época de dezembro. O maior equilíbrio entre acúmulo de reservas e a duração do subperíodo de enchimento de grãos favorece a formação de grãos mais pesados (Didonet et al., 2002), o que pode ter ocorrido na semeadura de outubro, quando se trabalhou com baixas densidades de plantas. Já o maior peso do grão, verificado na semeadura de agosto, nos níveis de manejo mais elevados, pode estar relacionado ao efeito compensatório da planta em aumentar o peso do grão quando há menor número de grãos por $\mathrm{m}^{2}$, se comparado com a semeadura de outubro e dezembro (Tabela 2).

A semeadura tardia propiciou a formação de grãos mais leves nos sistemas com alto investimento em manejo e nos potenciais, em relação às demais épocas de semeadura. Isto é atribuído ao fato de, na semeadura tardia, em relação às de agosto ou outubro, a maior parte do enchimento de grãos ocorrer em meses onde há redução expressiva na temperatura do ar e na radiação solar incidente, o que limita a atividade fotossintética e a translocação de carboidratos das frações vegetativas da planta aos grãos (Sangoi, 1993).

O peso do grão variou menos do que os demais componentes do rendimento, em função do nível de manejo adotado, o que corrobora as observações feitas por Otegui \& Andrade (2000) e Borrás \& Otegui (2001), de 
que este é o componente do rendimento menos afetado por variações nas práticas de manejo e no ambiente. De modo geral, o peso do grão teve pouca variação entre os tratamentos dentro da mesma época de semeadura, pelo fato de a taxa de enchimento ser uma característica genética (Didonet et al., 2002) que pode ser facilmente aumentada, sem resultar em prejuízos no rendimento final (Wang et al., 1999), e porque a sua duração apresenta baixa correlação com a temperatura do ar (Lozada \& Angelocci, 1999). Na semeadura de agosto, os níveis de manejo que receberam suplementação hídrica apresentaram grãos com maior peso do que os mantidos sob condições naturais de precipitação (Tabela 2). Nessa época de semeadura, o subperíodo de enchimento de grãos coincidiu com a ocorrência de um período de deficiência hídrica (Figura 1), o que limitou a síntese de carboidratos nas estruturas vegetativas e seu transporte aos grãos nos níveis de manejo baixo e médio.

A análise conjunta dos dados de rendimento de grãos, nos dois anos agrícolas, demonstrou que houve interação entre épocas de semeadura e nível de manejo (Tabela 2). Nos níveis de manejo baixo e médio, sem suplementação hídrica nas três épocas de semeadura, o rendimento de grãos obtido na época de semeadura de outubro, definida como preferencial quando não há limitação hídrica, foi similar ou inferior aos rendimentos obtidos nas semeaduras de agosto e dezembro (Tabela 2). Nesse caso, a maior disponibilidade de radiação solar incidente durante a floração e início do enchimento de grãos, propiciados pela semeadura de outubro, foi sobrepujada em importância pela atenuação da deficiência hídrica, obtida com as semeaduras de agosto e dezembro (Figura 1).

Os rendimentos de grãos obtidos nos níveis de manejo alto e potenciais I e II, todos com suplementação hídrica, foram maiores na semeadura de outubro em relação às demais (Tabela 2). Portanto, quando não há limitação hídrica no milho, e a densidade de plantas, o nível nutricional, o controle de pragas e invasoras e a genética são adequados, a coincidência do estádio de espigamento (maior área foliar) com os dias mais longos do ano (maior radiação solar) propicia incrementos significativos no rendimento de grãos (Silva \& Argenta, 2000). Desta forma, nos níveis de manejo alto e potenciais I e II, com ausência de limitação hídrica e nutricional, radiação solar em elevação e temperatura do ar moderada durante o desenvolvimento vegetativo, permitiram que plantas de milho da semeadura de outubro acumulassem mais carboidratos entre o pré e póspendoamento, aumentando o número de grãos por $\mathrm{m}^{2} \mathrm{e}$ o peso do grão (Tabela 2), conforme verificado por Borrás \& Otegui (2001).

Nas três épocas de semeadura e na média dos dois anos agrícolas, o rendimento de grãos foi incrementado até o nível de manejo potencial I (Tabela 2). Os maiores investimentos realizados no nível potencial II não se refletiram em incrementos no rendimento de grãos. Quando os valores de rendimento de grãos dos níveis de manejo propostos para potencializar o desempenho agronômico da cultura (Tabela 2) são comparados àqueles obtidos pelos produtores, constata-se que o fator limitante à elevação do rendimento é o manejo empregado no sistema (potencial genético da cultivar, arranjo de plantas, nível de adubação, controle de invasoras), desde que não ocorra limitação hídrica. Com isso, a adequação da época de semeadura com a menor probabilidade de ocorrência de deficiência hídrica, especialmente durante o período mais crítico de desenvolvimento da planta de milho, que ocorre da floração ao início do enchimento de grãos, pode incrementar o rendimento de grãos no Sul do Brasil.

O subperíodo emergência-pendoamento do milho, semeado em dezembro, coincide com os meses de temperatura atmosférica mais alta e maior disponibilidade de radiação solar da estação de crescimento (Figura 1). Isto acelera o crescimento e o desenvolvimento e estimula a respiração da planta, já que os processos metabólicos são mais ativos. Além disso, há maior incidência de pragas e moléstias, e o custo da irrigação é alto. Esses fatores diminuem o potencial de rendimento de grãos na época de dezembro (Sangoi, 2003).

Nas épocas de semeadura de agosto e outubro, houve vantagem econômica com a elevação do nível de manejo até o nível potencial I (Tabela 3). A resposta da margem bruta obtida nessas duas épocas, em função do nível de manejo, coincide com a verificada no rendimento de grãos, que também aumentou até o nível de manejo potencial I (Tabela 2). Mesmo tendo realizado a semeadura do milho em outubro, considerada melhor época para potencializar seu rendimento de grãos, o maior investimento no nível potencial II não elevou o rendimento de grãos e a margem bruta por hectare. Tais resultados confirmam os de Sangoi et al. (2003), que também não alcançaram retorno econômico ao maior 
investimento efetuado no potencial II do referido estudo. Na semeadura de dezembro, houve incremento da margem bruta por hectare somente até o nível de manejo médio (Tabela 3). Os investimentos realizados nos demais níveis não se refletiram em aumentos da margem bruta por hectare, justamente por causa do alto gasto efetuado nesses níveis, que, ainda assim, não conseguiu eliminar as restrições impostas pelo ambiente à obtenção de altos rendimentos de grãos.

O rendimento de grãos do milho apresenta alta resposta à melhoria do nível de manejo, embora isto requeira maior desembolso inicial dos produtores. A otimização do desempenho agronômico e econômico da cultura depende da interação entre as condições climáticas, o nível de manejo utilizado e o potencial produtivo da cultivar. Assim, em cada época de semeadura, as respostas do rendimento de grãos e do retorno econômico obtido com a cultura, ao sistema de manejo adotado, serão diferentes e dependerão da disponibilidade pluvial, radiação solar e das temperaturas mínimas e máximas do ar.

Tabela 3. Dispêndio, receita bruta e margem bruta relativos à cultura do milho em cinco níveis de manejo, em três épocas de semeadura, na média de dois anos agrícolas (2001/2002 e 2002/ 2003), em Eldorado do Sul, RS.

\begin{tabular}{lrcc}
\hline \multirow{2}{*}{$\begin{array}{c}\text { Nível de } \\
\text { manejo }^{(1)}\end{array}$} & \multicolumn{3}{c}{ Época de semeadura } \\
\cline { 2 - 4 } & Agosto & Outubro & Dezembro \\
Baixo & 400 & Dispêndio $\left(\mathrm{R} \$ \mathrm{ha}^{-1}\right)$ \\
Médio & 543 & 432 & 440 \\
Alto & 1.066 & 1.394 & 591 \\
Potencial I & 1.350 & 1.725 & 1.215 \\
Potencial II & 1.464 & 1.851 & 1.668 \\
\hline \multicolumn{3}{c}{ Receita bruta $\left(\mathrm{RS} \mathrm{ha}^{-1}\right)$} \\
Baixo & 1.166 & 1.028 \\
Médio & 1.456 & 1.073 & 1.026 \\
Alto & 1.652 & 2.363 & 1.441 \\
Potencial I & 2.466 & 3.164 & 1.817 \\
Potencial II & 2.430 & 3.251 & 2.075 \\
& \multicolumn{3}{c}{ Margem bruta $\left(\mathrm{R} \$ \mathrm{ha}^{-1}\right)$} \\
Baixo & 766 & 596 & 586 \\
Médio & 912 & 473 & 850 \\
Alto & 585 & 968 & 602 \\
Potencial I & 1.115 & 1.438 & 407 \\
Potencial II & 966 & 1.400 & 519 \\
\hline
\end{tabular}

(1)Os níveis de manejo variaram quanto ao tipo de cobertura de solo no inverno, à cultivar, aos níveis de adubação (base e cobertura), ao arranjo de plantas e ao regime hídrico.

\section{Conclusões}

1. Nas condições ambientais da Depressão Central do Rio Grande do Sul, a cultura do milho responde com maior elevação no rendimento de grãos, à melhoria das práticas de manejo, nas semeaduras de agosto e outubro.

2. A semeadura de outubro propicia maior rendimento de grãos do que as de agosto e dezembro, nos níveis com maior investimento em manejo.

3. O rendimento de grãos varia menos em função da época de semeadura quando o milho é conduzido sob condições naturais de precipitação.

4. Nas semeaduras de agosto e outubro, é possível associar máxima eficiência técnica com máxima eficiência econômica, por meio da melhoria do nível de manejo e da adoção de cultivares com maior potencial de rendimento.

5. Na semeadura tardia (dezembro), não há retorno econômico à utilização de sistemas de manejo destinados a potencializar o rendimento de grãos.

6. A elevação no rendimento de grãos com a melhoria do nível de manejo está associada, principalmente, à elevação dos números de espigas e de grãos por área.

\section{Agradecimentos}

Ao CNPq, pela concessão de bolsas de produtividade de pesquisa, de pós-graduação e de iniciação científica.

\section{Referências}

AITA, C.; GIACOMINI, S.J. Decomposição e liberação de nitrogênio de resíduos culturais de plantas de cobertura de solo solteiras e consorciadas. Revista Brasileira de Ciência do Solo, v.27, p.601612, 2003.

AMADO, T.J.C.; MIELNICZUK, J.; AITA, C. Recomendação de adubação nitrogenada para o milho no RS e SC adaptada ao uso de culturas de cobertura do solo, sob sistema plantio direto. Revista Brasileira de Ciência do Solo, v.26, p.241-248, 2002.

ANDRADE, F.H. Analysis of growth and yield of maize, sunflower and soybean grown at Balcarce, Argentina. Field Crops Research, v.41, p.1-12, 1995.

ANDRADE, F.H.; VEGA, C.; UHART, S.; CIRILO, A.; CANTARERO, M.; VALENTINUZ, O. Kernel number determination in maize. Crop Science, v.39, p.453-459, 1999.

ARGENTA, G.; SILVA, P.R.F. da; SANGOI, L. Arranjo de plantas em milho: análise do estado-da-arte. Ciência Rural, v.31, p.10751084, 2001.

BERGAMASCHI, H.; GUADAGNIN, M.R.; CARDOSO, L.S.; SILVA, M.I.G. Clima da Estação Experimental da UFRGS (e região de abrangência). Porto Alegre: UFRGS, 2003. 77p. 
BORRÁS, L.; OTEGUI, M.E. Maize kernel weight response to postflowering source-sink ratio. Crop Science, v.41, p.1816-1822, 2001. BUGBEE, B.G.; SALISBURY, F.B. Exploring the limits of crop productivity. I. Photosynthetic efficiency of wheat in high irradiance environments. Plant Physiology, v.88, p.869-878, 1988.

CONAB. Acompanhamento da safra 2003/2004. Sexto levantamento de safra/agosto de 2004. Disponível em: <http:// www.conab.gov.br/download/safra20032004lev06.pdf>. Acesso em: 29 dez. 2004.

DIDONET, A.D.; RODRIGUES, O.; MARIO, J.L.; IDE, F. Efeito da radiação solar e temperatura na definição do número de grãos em milho. Pesquisa Agropecuária Brasileira, v.37, p.933-938, 2002.

EVANS, L.T. Processes, genes, and yield potential. In: BUXTON, D.R.; SHIBLES, R.; FORSBERG, R.A.; BLAD, B.L.; ASAY, K.H.; PAULSEN, G.M.; WILSON, R.F. (Ed.). International crop science. Madison: Crop Science Society of America, 1993. v.1, p.687-696.

EVANS, L.T.; FISCHER, R.A. Yield potential: its definition, measurement, and significance. Crop Science, v.39, p.1544-1551, 1999.

GARDNER, F.P.; PEARCE, R.B.; MITCHELL, R.L. Physiology of crop plants. Ames: Iowa State University Press, 1985. 327p.

LOOMIS, R.S.; AMTHOR, J.S. Yield potential, plant assimilatory capacity, and metabolic efficiencies. Crop Science, v.39, p.15841596, 1999.

LOZADA, B.I.; ANGELOCCI, L.R. Efeito da temperatura do ar e da disponibilidade hídrica do solo na duração de subperíodos e na produtividade de um híbrido de milho (Zea mays). Revista Brasileira de Agrometeorologia, v.7, p.37-43, 1999.

MATZENAUER, R.; MACHADO, F.A. Disponibilidade hídrica para a cultura do milho em anos de El Niño, La Niña e neutros, nas regiões climáticas do Planalto Médio e Depressão Central do Rio Grande do Sul. Revista Brasileira de Agrometeorologia, v.10, p.67-74, 2002.
MINETTO, T.J. Custos de produção: lavouras em plantio direto. Porto Alegre: Fecoagro, 2001. 31p.

OTEGUI, M.; ANDRADE, F.H. New relationships between light interception, ear growth and kernel set in maize. In: WESTGATE, M.E.; BOOTE, K.J. (Ed.). Physiology and modeling kernel set in maize. Baltimore: Maryland, 2000. p.89-102. (Crop Science Society of America and American Society of Agronomy Special Publication, 29).

SANGOI, L. Aptidão dos campos de Lages (SC) para produção de milho em diferentes épocas de semeadura. Pesquisa Agropecuária Brasileira, v.28, p.51-63, 1993.

SANGOI, L. Understanding plant density effects on maize growth and development: an important issue to maximize grain yield. Ciência Rural, v.31, p.159-168, 2001.

SANGOI, L.; ARGENTA, G.; SILVA, P.R.F. da; MINETTO, T.J.; BISOTTO, V. Níveis de manejo na cultura do milho em dois ambientes contrastantes: análise técnico-econômica. Ciência Rural, v.33, p.1021-1029, 2003.

SILVA, P.R.F. da; ARGENTA, G. Ecofisiologia e fenologia das culturas do milho e do sorgo. In: PARFITT, J.M.B. (Ed.). Produção de milho e sorgo na várzea. Pelotas: Embrapa Clima Temperado, 2000. p.7-18.

STONE, P.J.; SORENSEN, I.B.; JAMIESON, P.D. Effect of soil temperature on phenology, canopy development, biomass and yield of maize in a cool-temperate climate. Field Crops Research, v.63, p.169-178, 1999.

TOLLENAAR, M.; LEE, E.A. Yield potential, yield stability and stress tolerance in maize. Field Crops Research, v.75, p.161-169, 2002.

WANG, G.; KANG, M.S.; MORENO, O. Genetic analyses of grainfilling rate and duration in maize. Field Crops Research, v.61, p.211222, 1999.

Recebido em 14 de fevereiro de 2005 e aprovado em 5 de outubro de 2005 